\title{
HIV infection and haemophilia
}

\author{
P Jones
}

Families with haemophilia are in turmoil. In developed nations those of their members who were infected with HIV as a result of advances in the management of their bleeding disorder are dying. Not unexpectedly, many seek compensation for their infection, and it is difficult to ease the bitterness and anger of their plight until they have had an answer to their call either from the courts or from the government. For the most part people with haemophilia in the developing nations escaped HIV infection because their families could not afford blood product treatment. Their escape from the epidemic may or may not add years to their lives, because without treatment haemophilia itself will take its toll. In addition the advent of HIV infection has made the delivery of such treatment harder, because the safe manufacture of virally inactivated products has decreased the yield of the relevant clotting factors with consequent escalations in cost.

Against this turbulant background are set the needs of the parents of newborn haemophilic sons-the new generation with everything to play for and so much to lose. Before AIDS their future seemed assured. Haemophilia was no longer a major cause of premature death in the severely affected populations of developed countries, and the incidence of crippling with haemophilic arthropathy of major synovial joints had fallen. True, optimism about the effects of recurrent hepatitis was being moderated as evidence of long term clinical sequelae appeared many years after primary infection. ${ }^{1}$ However, mortality from chronic liver disease had remained static for years and, certainly in terms of quality of life, the cost-benefit ratio was still very definitely in favour of multidonor blood product treatment with lyophilised factor VIII or IX concentrates. As well as the physical problems of haemophilia, associated social problems had also been eased considerably with contemporary therapy. Children with even the most severe forms of the disorder were able to attend normal school and compete in both the classroom and on the sports field with their nonhaemophilic peers. Most had the same prospects for higher education, and could look forward to good long term careers unhampered by pain and disability or insurance or travel restrictions. The dreams of many died with the knowledge that they had been infected with HIV, sometimes-because of the sex linked inheritance of their disorder-along with a grandparent, brothers, uncles, or cousins. The scenario has been compared with descriptions of the first world war, except that in the case of haemophilia and HIV infection there is no respite with wives or girlfriends; HIV can, of course, infect them too, and the children born to them.

\section{Present situation}

Cumulative cases of AIDS reported to the World Health Organisation as of 1 March 1990 totalled $237110 .^{2}$ Over half these cases (126 127) had been reported from the United States alone, suggesting considerable underreporting from many other countries. For instance, only 63842 cases were known for the whole of Africa, and 94 from South East Asia, most of these from either India (44) or Thailand (37). Within the eastern bloc, despite all the recent publicity, only 74 cases had been reported from Romania and 26 from the USSR. Of the 9449 people known to be HIV antibody positive in the United Kingdom, 3346 cases of AIDS had been reported by May $1990 .{ }^{3}$

To what extent these latter figures are a true reflection of the state of the epidemic in this country is debatable. Probably the most accurate information comes from the haemophilic cohort because, in order to define the scale of infection, most patients were tested for HIV antibody early in the epidemic, before the recognition of problems addressed in current pretest counselling, and they have since been followed up for both their haemophilia and their infection. Of the 1201 people with haemophilia known to have HIV infection in the United Kingdom 194 (16\%) had developed AIDS by the end of May 1990, and of these 130 had died. Details of the paediatric cases are shown in the table.

\section{Progression to disease}

With the exception of the newborn, who tend to fare badly, ${ }^{4-7}$ infection with HIV in childhood

Children and adolescents with haemophilia and HIV infection in the United Kingdom

\begin{tabular}{llllll}
\hline $\begin{array}{l}\text { Age } \\
\text { (years) }\end{array}$ & $\begin{array}{l}\text { No with } \\
\text { haemophilia } \\
\text { A and B }\end{array}$ & $\begin{array}{l}\text { No tested } \\
\text { for HIV }\end{array}$ & $\begin{array}{l}\text { No (\%) } \\
\text { positive }\end{array}$ & $\begin{array}{l}\text { No with } \\
\text { AIDS }\end{array}$ & $\begin{array}{l}\text { AIDS } \\
\text { deaths }\end{array}$ \\
\hline $0-14^{*} 863$ & 464 & $80(17)$ & 11 & 5 \\
$15-19$ & 424 & 305 & $128(42)$ & 9 & 4 \\
\hline
\end{tabular}

*No HIV infected child is below 5 years of age. The data in the table is courtesy of the United Kingdom Haemophilia Centre Directors, 1990. 
is usually followed by a prolonged latent period before the development of overt disease. Of the many variables that could influence the length of this period, only age has been shown to have a significant effect. An analysis of data from the continuing survey of 1201 HIV infected haemophiliacs by the UK Haemophilia Centre Directors showed that 85 had developed AIDS five years after seroconversion. ${ }^{8}$ The younger the age at seroconversion the better the prognosis. In this study $4 \%$ of those under 25 years, $6 \%$ of those between 25 and 44 years, and $19 \%$ of those over 45 years had progressed to AIDS. These results have now been analysed together with those from Hershey, New York, and Pittsburgh to give the risk of developing AIDS by 7 years. ${ }^{9}$ The authors conclude that, while it is likely that risk increases smoothly with age, $6 \%$ of those under 25 at seroconversion, $20 \%$ of those aged $25-44$, and $34 \%$ of those aged $\mathbf{4 5}$ or more have developed overt disease. They estimate that the chances of AIDS occurring in the three age groups within the next year are $2 \%, 10 \%$, and $11 \%$ respectively.

A similar finding, that only age at infection was found to have a statistically significant effect on the latent period, has recently been reported from a study of people infected as a result of blood transfusion. ${ }^{10}$

These and other studies of contributory factors that may influence the duration of infection have highlighted two of the difficulties in applying contemporary epidemiology to the counselling of infected individuals. Firstly, in most cases the date of infection is not known. Secondly, because a number of infected people die from causes other than those listed in the Centers for Disease Control case definition which is required for a diagnosis of AIDS, the true impact of HIV infection is always underestimated. In addition we may yet find that the overall prognosis for individuals with haemophilia may be influenced by concurrent infection with hepatitis B or C, and by difficulties in prescribing antiviral drugs in the presence of chronic liver disease or pancreatitis.

\section{Growth and HIV infection}

Perhaps surprisingly HIV infection seems to have little effect on the growth of haemophilic children, at least in asymptomatic patients. Pasi and his colleagues found no significant changes in the growth pattern of 27 boys followed up in Birmingham, despite the fact that some were symptomatic and one had developed AIDS. ${ }^{11}$ The findings of a comparative study of 83 haemophilic children, 41 with HIV infection, in the United States were in broad agreement, ${ }^{12}$ although the authors suggested that younger infected children may fare less well than older patients. They were also concerned about the histories of some individual children, and urged the setting up of a multicentre prospective study. In contrast to these preliminary findings in haemophilic children is the evidence of failure to thrive in those infected perinatally. ${ }^{6}$ Whether or not this effect is primarily due to HIV itself or to other factors including secondary disease, malnutrition, or deprivation remains to be seen. In the context of haemophilia treatment these questions are important because of continued doubts about the long term effects of frequent transfusion of multidonor blood products, most of which contain substantial amounts of extraneous protein in addition to the relevant clotting factor.

\section{Follow up and treatment}

With increasing recognition of HIV infection as a chronic disease in which early intervention may be beneficial to long term prognosis, there is a need to provide for the comprehensive care of patients and families well before the onset of AIDS. The parallels with haemophilia care are obvious, and established patterns of referral and management of haemophilia have acted as a template for HIV and AIDS. In brief, comprehensive haemophilia care recognises six basic needs of patients and their families: accurate diagnosis, effective and safe treatment, 24 hour cover, regular follow up, expert counselling, and a good standard of communication about the disorder. ${ }^{13}$ Because of the rarity of severe haemophilia much of this care falls to specialised hospital based units-the network of haemophilia centres-rather than to family doctors who usually have neither the experience nor the resources to treat the clotting factor deficiency. The same is true of HIV disease, although there will be exceptions, especially in areas of high prevalence. This is because, however good the support and counselling services within the community, the crucial medical need is for the prevention, or quick diagnosis and early treatment of opportunistic infections.

Most HIV infected haemophiliacs developing AIDS will present with Pneumocystis carinii pneumonia. Before this cardinal infection, oral candidiasis, herpes simplex, and herpes zoster are common, and we have noticed a flaring of acne in some adolescents who may otherwise complain of seborrhoeic dermatitis of face and scalp. Occasionally septic arthritis of a major joint occurs, and, short of aspiration, the differential diagnosis between infection and haemarthrosis can be difficult. Previous intercurrent exposure to hepatitis $B$ and $C$ viruses with subsequent underlying chronic liver damage may result in bouts of jaundice further complicating antiviral treatment. Infection with Mycobacterium avium intracellulare, or the appearance of a lymphoma are occasional terminal events. Kaposi's sarcoma is not a feature of HIV infection in the haemophilic population.

Many of these diseases can be prevented or at least ameliorated. All patients with persistently low or falling CD4 cell counts should be on prophylaxis for $P$ carinii pneumonia. Opinions differ as to the best drug to use, although the general consensus is that inhaled pentamidine isethionate is indicated after the first episode. ${ }^{14}$ The choice before this is between no prophylaxis, aerosol pentamidine, co-trimoxazole, dapsone, or pyrimethamine with or without sulfadoxine for asymptomatic patients ${ }^{15}$; current policy in the Newcastle Haemophilia Centre is to prescribe weekly dapsone.

Prevention of severe or sustained episodes of 
infection with candida is important both for the well being of the patient, and because oral or oesophageal thrush interferes with eating, adding to the problems of HIV associated weight loss and debility. Families should keep an antifungal preparation at home for use at the first sign of infection. Initially nystatin suspension is effective, but recurrent infection requires fluconazole. Similarly, early self medication with acyclovir will stem the development of herpes simplex infection, the painful and unsightly lesions of which can make life a misery for youngsters already very conscious of their body image and underlying disease. Although the local application of acyclovir cream is effective initially, recurrent infection demands early oral treatment. Seborrhoeic dermatitis usually responds to an antifungal (miconazole) or steroid cream and, when prevalent on the scalp, to a topical steroid (betamethasone $0 \cdot 1 \%$ ). Isotretinoin given under expert supervision may be needed to bring acne under control.

None of these measures has, of course, any effect on the underlying HIV disease, but there is increasing evidence that zidovudine (AZT, Retrovir) does. After a trial (protocol 019) of the drug in asymptomatic patients in the United States $^{16} 17$ the Food and Drug Administration (FDA) has recently extended the licence for zidovudine from its already established use in symptomatic people to symptom free HIV infected patients with CD4 counts below 500/ $\mu \mathrm{l} .{ }^{17}$ Given continued concern about possible long term side effects and the cost of the drug, it is not surprising that the rationale behind the FDA decision has been questioned, both in the United States ${ }^{18}$ and in Britain, ${ }^{19}$ where a Medical Research Council placebo controlled trial in asymptomatic patients (Concorde I) continues in association with the French INSERM organisation.

Neither the United States nor the European trial has included patients under 18 years of age, and recommendations for treatment below that age are sparse. Given current knowledge all that can be said is that zidovudine should be prescribed to all symptomatic children, and it should be seriously considered in all asymptomatic children with persistently low $(<500 / \mu \mathrm{l})$ or falling CD4 counts. Present dosage recommendations for adults (from the 019 trial) are $100 \mathrm{mg}$ zidovudine five times a day in waking hours.

Finally, there is now enough evidence to recommend that all HIV infected children should receive regular prophylaxis with intervenous gammaglobulin in order to correct hypogammaglobulinaemia and reduce the incidence of intercurrent infections. ${ }^{20-22}$ Although all children should have received routine active immunisation, with the exception of BCG which is contraindicated in HIV infection, the immunosuppression of the underlying disease results in progressive loss of antibody and booster doses or additional protection may be needed after exposure to infection. ${ }^{23}$

\section{Schooling}

With the exception of occasional flurries of parental or teacher anxiety in a few schools early in the course of the epidemic, the education of most HIV infected children has proceeded without hindrance. This has been due chiefly to the common sense of teachers, backed by the government publication on schoolchildren in May $1986,{ }^{24}$ and to the efforts of local education authorities and their medical advisors. Fundamental to this response was the evidence, which has remained unchanged with time, that HIV is not a contagious disease, with no risk of transmission in the everyday, non-sexual activities of school or work.

Also fundamental, to the care of children in particular, was the strong plea for the child's right to privacy that was made in the original government booklet, together with the recommendation that knowledge of infection be 'rigorously confined to those who need to know'. Although immensely reassuring to parents and infected youngsters it is perhaps unfortunate that this advice is still necessary today, because it implies that there is something different about HIV infection and AIDS that negates the usual rules governing the professional confidentiality of doctors and teachers. Without an appreciable change in public perception, however, people with HIV infection and their families will continue to be terrified of exposure, and in particular of the threat of attention by the more insalubrious sections of the media.

As a result, despite both official and individual reassurrance, it is still unusual for permission to be given to tell schoolteachers or school medical officers about the diagnosis. This interrupts the free exchange of information that can help children with learning or social difficulties, and must put the child with the secret knowledge of his or her infection at a special disadvantage. HIV infection is a very lonely condition to bear, especially when surrounded by active, healthy children working towards careers and future sexual and social lives unclouded by thoughts of disease and premature death. At least in the case of haemophilia teachers with knowledge of the primary diagnosis are able to make an informed guess and act accordingly, but where there are no clues infected children have to either divulge their status or be obviously sick before help can be given. One further point: paediatricians looking after cohorts of haemophilic children should not give a child's HIV antibody status, whether positive or negative, to the education or other authorities because this will lead by exclusion to diagnosis of HIV positive patients, sometimes erroneously.

\section{The adolescent}

For many people HIV infection forces dependence on others at precisely that time of life normally associated with increasing independence. This dependence has to be handled with sensitivity and recognition of individuality, so that the confidential trust that is of paramount importance to the care and management of the HIV infection can be established between the young person and his or her adviser. 
Those with haemophilia should be at an advantage here because of their close links with hospital staff over the years, ${ }^{25}$ although in some centres the transition from paediatric to adult care may mean that the relationships have to be broken at an especially difficult time. Whatever the background, all infected adolescents need time to express their views and concerns in private, and they need the discipline of regular informal appointments for both counselling and careful and reassuring physical examination. Specific attention should be paid not only to their general health but also to advice concerning their activities and interests and their future thoughts about competitive examinations and career. Not unexpectedly, it is easy for the infected adolescent to give up all hope of a structured and worthwhile future. Not only do they feel cut off from their peers because of their infection and the secrecy surrounding it, but they sometimes see no point in trying to achieve anything.

Friendly inquiry should be made about their use of alcohol, tobacco, and drugs and about diet, sleep, and their family and other relationships. The normal vulnerability of adolescent boys and girls can be made intolerable by the difficulties imposed by HIV infection on the establishment of normal loving relationships. Sometimes the person to help guide youngsters through these difficulties is a mature practice nurse or young counsellor, rather than a doctor, social worker, or psychologist. Whoever undertakes the task must be prepared to give repeated help when it is needed. Of the many publications written to help people come to terms with the problems of sexuality and HIV infection, one of the best is that recently published by the British Haemophilia Society. ${ }^{26}$

During sessions with infected adolescents, topics that should be covered in addition to those already mentioned and with reference to the age and maturity of the youngster, include repeated reassurance about casual spread, sexual relationships, the prevention of infection in others, and death and bereavement. ${ }^{27}$ The adolescent should be given the means for immediate access to help, including the free provision of condoms and advice about their use and that of preparations containing nonoxinol 9. He or she should know that nursing will be by people already known to them if hospital admission is necessary, and that financial help will be made available for friends and family making visits to the clinic or ward.

Most adolescents will wish to share fully in knowledge about their progress and the results of investigations, coupled with information about currently available treatment. Concerns about the availability and wisdom of such treatment, often fostered by ill conceived television programmes, are easily transmitted to patients and add to the uncertainties associated with their underlying disease.

\section{Current treatment of haemophilia}

Most HIV infection in the haemophilic population occurred before the virus was discovered and therefore before individual donor testing was introduced. As a result of the exclusion of high risk donors, HIV antibody testing, and the treatment of concentrates to remove viruses no further cases of infection have been reported since 1986. Although initial attempts at viral elimination using dry heat sometimes failed, ${ }^{28-31}$ newer methods involving the use of monoclonal antibodies together with heating, or solvent/ detergent breakdown of the fatty envelopes of HIV and other viruses seem very safe, as does prolonged dry heating at $80^{\circ}$ for 72 hours in the final phial, which is the method presently in use in the UK. However, after all that has happened no-one is foolish enough to give an absolute guarantee on the safety of any product, and occasional reports of failure to eliminate hepatitis C still occur. ${ }^{32}$

People with severe or moderately severe haemophilia who need factor VIII or factor IX replacement therapy should no longer be treated with fresh frozen plasma or cryoprecipitate, because these products cannot yet be treated in any way to remove virus that has remained undetected on individual donor testing. The choice for them therefore lies between the Bio Products Laboratory concentrates (or the equivalent products of the Scottish Blood Transfusion Service), the products of the French company Bio-Transfusion which also come from volunteer donors but are treated with solvent/detergent, or, in the case of factor VIII, the two commercial products prepared from the plasma of paid donors that have full licences in the UK. They are Monoclate-P, manufactured by Armour, which is prepared by monoclonal antibody separation together with pasteurisation, and Profilate, which is manufactured using the solvent/detergent method by Alpha. Neither the British nor the BioTransfusion products are yet licenced in the UK, although the latter do have full French licences. Whichever product HIV and hepatitis $\mathrm{C}$ negative patients receive they must continue to be followed up regularly and agree to regular testing for evidence of infection. This is because it has not proved possible to identify HIV in individual phials of factor VIII or IX, and evidence of safety must therefore depend on careful epidemiological surveillance. Mildly affected haemophilia A patients should, when possible, be treated with desmopressin (DDAVP) rather than blood products as should carriers, and people with type I von Willebrand's disease. All patients with a haemostatic disorder that may need blood product correction at some time should still be vaccinated against hepatitis $B$, as should staff involved in their care.

\section{Compensation}

The governments of many countries have responded to appeals from haemophilic families for extra help in order to cope with HIV infection and AIDS. ${ }^{33}$ Within the UK this response has been based on recognition that HIV infection has resulted in additional hardship for a group of people with pre-existing handicap. Two payments have been made, the first of $£ 10 M$ into a trust fund in 1987 (the Macfarlane Trust), ${ }^{34}$ and the second, in 1990, of individual 
ex-gratia payments of $£ 20000$ to the estimated 1200 people with haemophilia and HIV infection.

Given the nature of their infection it is not surprising that these measures, although very welcome, have failed to stop legal action, and some 950 people are currently seeking substantial compensation through the courts. The magnitude of the task facing both plaintiffs and the defence is formidable, and although everyone concerned is aware of the urgency involved as AIDS takes its toll in the haemophilic population, it is unlikely that, without government intervention, a decision will be reached before the autumn of 1991. In the meantime the action causes additional misery, both because of difficulties in the hospitals and departments concerned and, more importantly, because of the disruption of the normal human processes of adaptation and grieving that cannot progress until the dispute is resolved one way or the other.

1 Triger DR, Preston FE. Chronic liver disease in haemophiliacs. $\mathrm{Br} \mathcal{F}$ Haematol 1990; 74:241-5.

2 Anonymous. Statistics from the World Health Organization and the Centers for Disease Control. AIDS 1990;4:605-10.

3 Anonymous. Communicable diseases report 90/24. London: UK Communicable Diseases Surveillance Centre and Communicable Diseases (Scotland) Unit, 15 June 1990.

4 European Collaborative Study. Mother-to-child transmission of HIV infection. Lancet 1988;ii:1039-42.

5 Italian Multicentre Study. Epidemiology, clinical features, and prognostic factors of paediatric HIV infection. Lancet 1988;ii:1043-5.

6 Task Force on Pediatric AIDS. Perinatal human immunodeficiency virus infection. Pediatrics 1988;82:941-4.

7 Scott GB, Hutto C, Mukach RW, et al. Survival in children with perinatally acquired human immunodeficiency virus with perinatally acquired human immunodeficiency
type I infection. $N$ Engl $f$ Med 1989;321:1791-6.

8 Darby SC, Rizza CR, Doll R, et al. Incidence of AIDS and excess mortality associated with HIV in haemophiliacs in excess mortality associated with HIV in haemophiliacs in
the United Kingdom: report on behalf of the directors of the United Kingdom: report on behalf of the directors of 298: 1064-8.

9 Darby SC, Doll R, Thakrar B, et al. Time from infection with HIV to onset of AIDS in patients with haemophilia in the UK. Statistics in Medicine 1990;9:681-9.

10 Blaxhult A, Granath F, Lidman K, Giesecke J. The influence of age on the latency period to AIDS in people infected by HIV through blood transfusion. AIDS 1990;4:125-9.

11 Pasi KJ, Collins MA, Ewer AK, Hill FGH. Growth in haemophilic boys after HIV infection. Arch Dis Child 1990; 65:115-8.

12 Jason J, Gomperts E, Lawrence DN, et al. HIV and hemophilic children's growth. Fournal of the Acquired Immune Deficiency Syndrome 1989;2:277-82.

13 Jones P. Living with haemophilia. 3rd Ed. Tunbridge Wells: Castle House Publications, 1990:217-9.
14 Centers for Disease Control. Guidelines for prophylaxis against pneumocystis carinii pneumonia for persons 1989;38: 1-9.

15 Klein RS. Prophylaxis of opportunistic infections in individuals infected with HIV. AIDS 1989;3(suppl 1): individuals.

16 Volberding PA, Lagakos SW, Koch MA, et al. Zidovudine in asymptomatic human immunodeficiency virus infection. $N$ Engl f Med 1990;322:941-9.

17 Friedland GH. Early treatment for HIV: the time has come. $N$ Engl f Med 1990;322:1000-2.

18 Medical News and Perspectives. Controversy continues as experts ponder zidovudine's role in early HIV infection. JAMA 1990;261:1605.

19 Anonymous. Zidovudine for symptomless HIV infection. Lancet 1990;335:821-2.

20 Oleske JM, Connor EM, Bobila R, et al. The use of IVIG in children with AIDS. Vox Sang 1987;52:172.

21 Stiehm ER. Human gamma globulins as therapeutic agents. Adv Pediatr 1988;35:50.

22 Hague RA, Yap PL, Mok JYQ, et al. Intravenous immunoglobulin in HIV infection; evidence for the efficacy of treatment. Arch Dis Child 1989;64:1146-50.

23 Departments of Health. Immunisation against infectious disease

24 Department of Education and Science and Welsh Office. Children at school and problems related to AIDS. London: HMSO, 1986.

25 Jones $P$. The counselling of HIV antibody positive haemophiliacs. In: Green J, McCreanor A, eds. Counselling in HIV infection and AIDS. Oxford: Blackwell Scientific Publications, 1989:108-20.

26 The Haemophilia Society. Haemophilia, HIV and safer sexthe choice is here. London: The Haemophilia Society, 1990.

27 Jones P. HIV and AIDS. Living with haemophilia. 3rd Ed. Tunbridge Wells: Castle House Publications, 1990: 191-204.

28 White GC, Matthews TJ, Weinbold KJ, et al. HTLV-III seroconversion associated with heat-treated factor VIII concentrate. Lancet 1986; $611-2$.

29 van den Berg W, ten Cate JW, Breederveld C, Goudsmit J. Seroconversion to HTLV-III in haemophiliac given heattreated factor VIII concentrate. Lancet 1986;i:803-4.

30 Centers for Disease Control. Survey on non-US haemophilia treatment centers for HIV seroconversions following treatment centers for HIV seroconversions following
therapy with heat-treated factor concentrates. MMWR therapy with

31 Williams MD, Skidmore SJ, Hill FGH. HIV seroconversion in haemophilic boys receiving heat-treated factor VIII concentrate. Vox Sang 1990:58:135-6.

32 Berntorp E, Nilsson IM, Ljung R, Widdell A. Hepatitis C virus transmission by monoclonal antibody purified factor VIII concentrate. Lancet 1990;335:1531-2.

33 News. Blood, HIV, and compensation. BMF 1990;300:67-8. 4 Anonymous. Haemophiliacs (financial assistance). House of Commons Official Report (Hansard). 1987 November 16: cols $773-81$.

\section{Addendum}

In December 1990 the government offered to settle the UK legal action without admission of liability. As we go to press the terms of this offer are being considered by the families involved. Claims for compensation continue in other countries. 